\title{
Correlation of Physical Activity and Menopause Symptoms
}

\author{
Retnayu Pradanie \\ Faculty of Nursing Universitas Airlangga \\ Surabaya, Indonesia \\ retnayu-p@fkp.unair.ac.id
}

\author{
Eka Misbahatul Mar'ah Has \\ Faculty of Nursing Universitas Airlangga \\ Surabaya, Indonesia \\ Tutik Malichah \\ Faculty of Nursing Universitas Airlangga \\ Surabaya, Indonesia
}

\begin{abstract}
Menopausal women often experience a decrease in the production of Estrogen, progesterone and other sex hormones. The most common symptoms that occur during perimenopause period, for example; hot flashes, insomnia, irritability, and mood instability, thinning of vaginal mucosa with decreased lubrication. The purpose of this study was to identify a correlation between physical activity and Menopause symptoms in women aged 41-50 years. Design used was correlational research. Population comprised women aged 41-50 years at Village Gogik district of Ungaran Barat. The sample was taken by simple random sampling technique, obtaining as many as 117 respondents. Physical activity as independent variable and menopause symptoms as the dependent variable. Their physical activity levels were assessed using the General Practice Physical Activity Questionnaire (GPPAQ). The Menopause Rating Scale (MRS) questionnaire was used to assess menopause symptoms. Data obtained were processed using Spearman's Rho with $\alpha \leq \mathbf{0 . 0 5}$. Results showed that $p$ (Sig.) $=0.000, r=-0.950$, indicating that physical activity variables had a negative very strong correlation with menopause symptoms In women aged 41-50 years. In conclusion, physical activity correlates with menopause symptoms in women aged 41-50 years. Nurses can provide health education about the importance of exercise to minimize the effect of menopause symptoms.
\end{abstract}

Keywords: physical activity, menopausal symptoms, women aged 41-50 years

\section{INTRODUCTION}

Menopause is the end of the menstrual cycle period on the woman and diagnosed after women does not have a menstrual period for 12 months [1]. A woman who reaches age 45 experiencing ovaries degeneration, hence decreasing estrogen level. The body's hormonal system suffered a functional decline. Changes in hormone secretion cause changes in the physical and psychological condition [2]. Symptoms of menopause can occur in women aged 41-50 years with symptoms include hot flashes, insomnia, irritability and mood instability, thinning of the vaginal mucosa with decreased lubrication. Complaints on menopausal symptoms are highly individualized influenced by nutritional status, stress, knowledge, social, economic, and physical exercise [3].

According to data from the WHO, the population of postmenopausal women increases every year which is around $3 \%$ [4]. In Indonesia, the growth of women is higher than men. According to the BPS report in 2008, the ratio of females and males is 100: 96.49 [5]. As for the life expectancy of the population of Indonesia (male and female) rise from 67.8 years in the period, 2000-2005 become 73.7 years in the period 2020 to 2025 with an estimated total population of Indonesia will reach 273.65 million in 2025. Along with increasing life expectancy have an impact on the growing number of menopause, accompanied by the emergence of symptoms of menopausal complaints. Although not fatal, symptoms of menopause can cause discomfort and can lead to interruptions in daily employment [6].

Research conducted by the Department of Epidemiology and Psychiatry, University of Pittsburgh O'Hara discovered that $28.9 \%$ women experienced stress (not ready) at the start of perimenopause, $20.9 \%$ in premenopausal and $22 \%$ in postmenopause. Visitation number of women aged 41 50 years at Ungaran health centers increased per year. In 2012-2013, the number of visits was 214, and the reason for visiting health center was suffered from menopause symptoms, in 2013-2014 increased by 232 people. Based on an initial survey on Gogik in 2914 there were 172 women aged 41-50 years. While the number of visits complaints of menopausal symptoms in 2014 as many as 98 people and 76 women between January-October 2015 complained about dyspareunia, insomnia, migraines, and experience hot flashes. They ask for medicines to relieve the symptoms. 
Symptoms of menopause should be treated as a natural, effective and safe to reduce complaints and improve the quality of life [7] [8]. It is suggested doing physical exercises to deal with the symptoms of menopause. Physical exercise can be walking, aerobics, or fitness. Physical activity can balance hormonal changes, reduced physical and psychological complaints, strengthen bones and prevent osteoporosis, prevent heart disease, as well as increase endurance [9]. Physiologically, physical exercise such as gymnastics can increase capacity aerobic, strength, flexibility and balance as well as the influence formation of bone. Psychologically, physical exercise can improve mood, reduce the risk of dementia, and prevent depression. Socially, exercise can physically reduce dependence on others, got many friends and increase productivity [10].

Although the benefits of physical activity are numerous, the phenomenon shows the number of women who are facing symptoms menopause is sometimes reluctant to do sports. The reason often stated for not exercising is a lack of time availability [11]. Based on that phenomenon, the purpose of this research was to explain the correlation between physical activity index with symptoms of menopause among women age 41-50 in Gogik, West Ungaran.

\section{METHODS}

\section{A. Design}

This study uses a correlational study design. The population in this study were premenopausal women 41-50 years of age, able to read and write, do not have a physical disability that interferes with the activity and is not undergoing hormone replacement therapy in the Village of West Ungaran sub district gogik many as 143 people. Based on a sample size calculation formula and simple random sampling technique obtained a sample of 117 people.

Physical activity questionnaire consists of three domains brief questions related to jobs, activities over the past week as well as on foot. The results of the answers to these questions categorized according to the Physical Activity Index (PAI) into 4 levels of activity including Active, Moderately Active, Inactive Moderately, and Inactive [12]. Menopause Rating Scale (MRS) questionnaires consist of 11 questions with Likert scale criteria (does not exist: 0 , mild: 1 , medium: 2, Weight: 3, very heavy: 4). Score then summed and have meaning 0: asymptomatic, 44: the highest level of complaints. The questionnaire was fulfilled using interview, and any additional data will be noticed as field notes.

This study has been declared ethically eligible by health research ethics committee Faculty of Medicine Universitas Airlangga with the number 351 / EC / KEPK / FKUA / 2015.

\section{RESULTS}

The level of physical activity of respondents indicated that most respondents were in active moderate level of physical activity as much as 37 people (31.6\%), moderate inactive were 35 (29.9\%), active as many as 24 people (20.5\%), inactive as many as 21 people (17.9\%). While the score menopause rating scale (MRS), which obtained the lowest score 1 and the highest score is 29. Based on complaints of menopausal symptoms gained 111 people (95\%) complained of symptoms somato-vegetative, 106 people (91\%) complained of symptoms of urogenital, and 95 people (81\%) complained of psychological symptoms.

The results of the statistical test obtained using Spearman's rho showed $\mathrm{p}=0.000$ with correlation coefficients $(r)=-0.950 .21$ respondents had an inactive level of physical activity, at most that number 6 respondents with a score of MRS 22. Next of 35 respondents to the Inactive Moderate levels of physical activity, at most that number 6 respondents with a score of MRS 17.

6 of the 21 respondents to the level of physical activity Inactive, has an MRS score of 22. 6 of 35 respondents to the Inactive Moderate levels of physical activity, has a score of MRS 17. 18 Of the 37 respondents to have the level of physical activity Moderate Active high score MRS 6. and 9 out of 24 respondents to the level of physical activity Active, the number has a score MRS 2. Thus there is a relationship (correlation) between physical activity and symptoms of menopause in women ages 41-50 Gogik year in the Village District of West Ungaran. The value of the correlation coefficients of -0.950 which indicates that this correlation has a very strong force in the direction of negative relationships or opposite meaning if physical activity is high then low menopausal symptoms, and vice versa if physical activity is low, the symptoms of menopause will be high.

\section{DISCUSSION}

According to the distribution of respondents by occupation, respondents who worked in private sector as many as 40 people (34.2\%) while working as a civil servant at least 7 people (6\%). Private sector worker, part of them were factory workers, office employees and the rest are selfemployed. Working hours of the factory workers varied from $07.00 \mathrm{am}$ to $17.00 \mathrm{pm}$ and there also morning, afternoon, evening shifts. For women who work as farmers, they help grow rice, mowing, even hoeing fields, when the harvest season comes they help harvest and sell it to the market. They go to the field from 08:00 pm until the afternoon sometimes break at noon for prayer and lunch. For women with a profession of civil servants, most of them are 61 teachers; they work from morning until noon. Women who are selfemployed, most of them were open a stall in the house, tailor, create businesses such as catering, accessories, salon while managing the household. Women who do not work, they spend the time to take care of the household, taking care of children, cleaning the house and gardening.

Physical activity is any movement of the body due to muscle activity - skeletal muscles resulting in energy expenditure. Physical activity consists of the activity of work, sleep, and in the spare time. Physical exercises are planned, structured, made repeatedly. Sports are part of the physical activity [13]. According to Heinemann, physical exercise and daily physical activity can contribute to maintaining health, simple physical activities such as gardening and walking [14]. 
The number of women facing menopause symptoms sometimes reluctant to do sports [11]. Reasons often cited for not exercising is a lack of availability of time. This is by the conditions of women aged 41-50 years in Gogik village mostly work as factory workers and farmers. However, such work also indirectly trigger women to have greater physical activity. In women who do not work or are self-employed, they tend to spend more time to take care of housekeeping, cleaning, and gardening can also trigger female to perform more activities. Also, there were several weekly gymnastics for the women in the neighborhood environment.

The distribution of data about the symptoms of menopause in women aged 41-50 years showed that 18 women (15.4\%) had score 6 , but there was also one respondent had the score 4, 12, 13, 25, 29 for each of them. On a score of 6 and 4, the respondents experience some symptoms of menopause in light intensity, while the respondents with a score of 12 and 13 experience some symptoms of menopause with intensity mild to moderate, and scores of 25 and 29 respondents had any menopausal symptoms with mild to severe intensity. The most common complaints are felt, as many as 111 respondents had complaints somatic-vegetative form joint complaints (discomfort in the joints, pain in the joints), sweating/flush, heart complaints, and sleep disorders. A total of 106 respondents experienced urogenital complaints include changes in sexual desire, Bladder problems (difficulty urinating, frequent urination, urination uncontrolled), and vaginal dryness. While as many as 95 respondents experienced psychological problems such as depression, irritability, anxiety, and fatigue.

According to Purwoastuti \& Walyani, menopausal symptoms are complaints that arise during the premenopausal [15]. Endocrinological menopause symptoms is a drop in estrogen levels, increased levels of gonadotropins (FSH and LH). Known also as Estrogen deficiency syndrome. Time climacteric is a period of adjustment from one woman to the decline in production of hormones produced by the ovaries and their impact on the hypothalamic-pituitary axis and target organs. Lack of estrogen causes a decreased function of organs that depend on this hormone, such as the ovaries, uterus, and endometrium. The strength and flexibility of the vagina and vulva tissues decrease, and eventually, all the networks that depend on estrogen will atrophy.

According to Reeder with a decrease in estrogen, neurotransmitters decrease the activity of opioid endorphin and modify the metabolism on dopamine and serotonin [3]. Fluctuations in hormone levels that contribute to emotional changes. The physiological impact of perimenopause can cause women to experience a variety of symptoms. Changes in vaginal mucosa vary among perimenopause women. In fact, minimal changes can cause pain during intercourse (dyspareunia). Dyspareunia is a common symptom that should not be overlooked in the treatment of postmenopausal women.

Menopause symptom scores on the respondents are likely influenced by the socio-economic background of rural communities where the symptoms of menopause are still regarded as a natural thing with age, but it is the habit of ignoring rural communities if a complaint has not become a nuisance to them. Knowledge factors also affect the perceived symptoms of menopause, when asked about the symptoms menopause average respondent only knows that the signs of menopause symptoms are menstrual start sparse and irregular, vaginal dryness and decreased sexual desire. Factors such as gymnastics physical exercise every week they follow likelihood to affect the symptoms of menopause and the factors that make the work of the women are not too bothered by menopausal symptoms appear.

The results of data analysis showed a significant correlation between physical activity with the symptoms of menopause in women aged 41-50 years in the village of Gogik. This shows that if the lowest physical activity level that is at the inactive level, the menopause symptom score (MRS) increases. However, when women are at the highest level of physical activity that is active, then the menopausal symptom score (MRS) are perceived decline. According to[14], physical exercise and daily physical activity can contribute to maintaining a healthy, simple physical activities to do such as gardening and walking. According to [16] [16] high-intensity physical activity to effectively compensate for the most negative changes associated with the menopause transition. Changes in estrogen levels also resulted in a decrease in beta-endorphins. At the time of the activity physically performed, the pituitary gland to increase production of beta-endorphin and as a result, the concentration of beta-endorphin in the blood rises to the brain so that it can reduce pain, anxiety, depression, and feelings of fatigue.

Therefore, an increase in physical activity can reduce the symptoms of menopause and enhance a feeling of comfort, which in turn will improve the quality of life [17]. In women aged 41-50 years in the village Gogik is at the level of physical activity of moderate activity and has a score of menopausal symptoms tend to be mild. This is consistent with some previous theories that said that physical exercise is one of the factors that influence the symptoms of menopause. Also, previous studies to examine the benefits of physical activity for women was found not only to brain function and functional capacity but also effective in reducing the symptoms of somatic and psychological symptoms such as depression and anxiety [18] [19] This looks at the psychological symptoms experienced by women tend to be mild or absent in women with levels moderate physical activity is active or active. In women who regularly follow the psychological gymnastics every week can improve mood, reduce the risk of dementia, and preventing depression because during exercise the mind will be focused on the sports movement and the increased blood flow to the brain that will make their brain fresh. Socially, the sport can reduce the dependence on others, got many friends and increase productivity so that the 66 menopause symptoms that appear automatically distracted. 


\section{CONCLUSION AND RECOMMENDATION}

Women aged 41-50 years in the village of Gogik most are in the active moderate level of physical activity, because most women work as factory workers and farmers, except that there are some women who regularly follows the weekly gymnastics. They also mostly experienced somatic-vegetative complaints in the form of joint complaints (discomfort in the joints, pain in the joints), sweating/flush, heart complaints, and sleep disturbance. There was a negative correlation between physical activity and menopausal symptoms if physical activity is high then low menopausal symptoms, and if physical activity is low, the symptoms of menopause will be high.

Nurses can improve public knowledge about the importance of physical activity to minimize the symptoms of menopause through counseling, distribution of leaflets and individual consultation. For further research can be held in a qualitative perspective so that the answer given was totally in line with what respondents felt at that moment.

\section{References}

[1] E. Kusmiran, Kesehatan Repoduksi Wanita dan Remaja. Jakarta: Salemba Medika, 2012.

[2] I. B. G. Manuaba, Memahami Kesehatan Reproduksi Wanita, 2nd ed. Jakarta: EGC, 2009.

[3] S. J. Reeder, Keperawatan Meternitas. Jakarta: EGC, 2011.

[4] A. Baziad, Kontrasepsi Hormonal. Jakarta: PT. Bina Pustaka Sarwono Prawirohardjo, 2008.

[5] Badan Pusat Statistik, "Jumlah Penduduk Pertengahan Tahun Hasil Proyeksi Penduduk, 2010-2020.,”2015. .

[6] H. Varney, M. J. Kriebs, and L. C. Gegor, Buku Ajar Asuhan Kebidanan. Jakarta: EGC, 2007.

[7] National Institutes of Health., "NIH State-of-theScience Conference Statement on management of menopause-related symptoms," NIH Consens.

State-of-the Sci. Statements, vol. 22, no. 1, pp. 138, 2005.

[8] A. Daley, C. MacArthur, H. Stokes-Lampard, R. McManus, S. Wilson, and N. Mutrie, "Exercise participation, body mass index, and health-related quality of life in women of menopausal age," $\mathrm{Br}$. J. Gen. Pract., vol. 57, no. 535, pp. 130-135, 2007.
Menopause: A Guide to Physical, Emotional and Spiritual Health at Midlife and Beyond. Florida: Deerfield Beach, 2003.

[10] F. R. P. C. Pérez-López and J. M. TroyanoLuque, "Peri- and post-menopausal incidental adnexal masses and the risk of sporadic ovarian malignancy: new insights and clinical management," Gynecol. Endocrinol., vol. 26, no. 9, pp. 632-643, 2010.

[11] D. Kasdu, Kiat Sehat dan Bahagia di Usia Menopause. Jakarta: Puspa Swara, 2015.

[12] Ipaq, "Guidelines for Data Processing and Analysis of the International Physical Activity

Questionnaire ( IPAQ ) - Short and Long Forms,” Ipaq, no. November, pp. 1-15, 2005.

[13] W. L. Haskell et al., "Physical activity and public health: updated recommendation for adults from the American College of Sports Medicine and the American Heart Association," Circulation, vol. 116, no. 9, p. 1081, 2007.

[14] W. Heinemann, The Womens Health Book. Australia: The Royal Women's Hospital Foundation, 2014.

[15] P. Walyani and E. Purwoastuti, "Asuhan Kebidanan Kegawatdaruratan Maternal \& Neonatal.” Yogyakarta: Pustaka Baru Press, 2015.

[16] W. Kemmler, S. Von Stengel, J. Weineck, D. Lauber, W. Kalender, and K. Engelke, "Exercise effects on menopausal risk factors of early postmenopausal women: 3-Yr erlangen fitness osteoporosis prevention study results,” Med. Sci. Sports Exerc., vol. 37, no. 2, pp. 194-203, 2005.

[17] E. McAuley, B. Blissmer, J. Katula, T. E. Duncan, and S. L. Mihalko, "Physical activity, self-esteem, and self-efficacy relationships in older adults: A randomized controlled trial," ann. behav. med, vol. 22, p. 131, 2000.

[18] K. Mirzaiinjmabadi, D. Anderson, and M. Barnes, "The relationship between exercise, Body Mass Index and menopausal symptoms in midlife Australian women," Int. J. Nurs. Pract., vol. 12, no. 1, pp. 28-34, 2006.

[19] J. M. Lojovich, “The relationship between 
aerobic exercise and cognition: is movement medicinal?,” J. Head Trauma Rehabil., vol. 25,

no. 3, pp. 184-192, 2010. 